\title{
Whipple's disease confined to the brain: a case studied clinically and pathologically
}

\author{
F. C. A . R O M A N UL, J . R A D V A N Y, A N D R. K. R OSA L E S \\ From the Departments of Neurology and Pathology, Boston University School of Medicine and Boston \\ Veterans Administration Hospital, Boston, Massachusetts, USA
}

SUMMARY A 40 year old man developed seizures, intermittent fever, and progressive dementia ending in coma and death after four years. The cerebrospinal fluid showed variable pleocytosis and occasional elevation of protein. The necropsy revealed many lesions characteristic of Whipple's disease confined to the grey matter of the brain. The pathological changes were studied with the light and electron microscope. The findings permitted an understanding of the temporal sequence of changes in the lesions. Involvement of the brain in this condition is rare, but the disease is treatable and the diagnosis can be made by brain biopsy.

After Whipple's definition of the disease in 1907 , only 15 cases of this condition were reported over a period of 43 years (Hendrix et al., 1950). From 1950 until 1970, the number of cases in the literature increased to 114 (Maizel et al., 1970), and by now it is much larger. We found 21 published cases in which the characteristic lesions of the disease were present in the brain in addition to the other organs and tissues (see Discussion). The purpose of this communication is to report a case which is unique in that both the symptoms and the pathological changes were confined to the brain. Another aim is to present some interesting features of the pathology.

\section{Case report}

\section{HISTORY}

This patient was well until May 1970 when, at the age of 40 years, he developed severe headaches for three days followed by major motor seizures. Admitted to hospital, he was found to have a left extensor plantar response. Studies including EEG, lumbar puncture, and right carotid arteriogram, were negative. He was discharged on diphenylhydantoin $300 \mathrm{mg}$ a day, but continued having seizures with olfactory aura, lips smacking, and right hand shaking. In July 1970 he was readmitted to the same institution. A lumbar

\footnotetext{
Address for reprint requests: Dr F. Romanul, Department of Neurology, Boston University School of Medicine, 80 East Concord Street Boston, Massachusetts 02118, USA.

Accepted 5 April 1977
}

puncture showed clear cerebrospinal fluid under normal pressure, containing 160 erythrocytes, seven polymorphonuclear leucocytes, and 45 lymphocytes $/ \mathrm{mm}^{3}$, protein $0.68 \mathrm{~g} / 1$, and sugar $2.9 \mathrm{mmol} / 1(52 \mathrm{mg} / \mathrm{dl})$. A left carotid arteriogram and a pneumonencephalogram were indicative of a left anterior temporal space-occupying lesion. The seizures were controlled on diphenylhydantoin and primidone and he was discharged. Because of headache and confusion, in December 1970 he was readmitted. On examination he had decreased attention span, poor recent memory, and swollen optic discs with fresh haemorrhages. The lumbar puncture revealed clear cerebrospinal fluid under a pressure of $180 \mathrm{mmH}_{2} \mathrm{O}$, containing 950 erythrocytes, six polymorphonuclear leucocytes, and 25 lymphocytes $/ \mathrm{mm}^{3}$, protein $0.16 \mathrm{~g} / 1$, and sugar $3.8 \mathrm{mmol} / 1(68 \mathrm{mg} / \mathrm{dl})$. Arteriography revealed apparent increase in size of the temporal lobe mass which led to surgical resection of the anterior portion of the left temporal lobe. Pathologically, the specimen was found to contain multiple lesions interpreted to represent a granulomatous encephalitis of unknown type. He was maintained on anticonvulsant medications, chlorpromazine and methylprednisolone.

In March 1971 he was transferred to the Boston Veterans Administration Hospital. The general physical examination was normal. Spontaneously he uttered occasional short sentences. When addressed, he looked at the examiner, but did not answer or perform any requested tasks. There was paratonic rigidity in all the limbs, suck, snout, and grasp reflexes, and bilateral extensor plantar 
responses. The EEG showed bilateral theta and delta slow wave activity. The brain scan revealed diffusely increased uptake of isotope in both Sylvian regions. He developed daily temperature elevations with occasional spikes to $39^{\circ} \mathrm{C}$. $\mathrm{Re}$ peated blood cultures, tests for collagen vascular disease and serum VDRL were negative. Urine cultures at various times showed either Pseudomonas, Klebsiella or Proteus. He was treated sequentially with ampicillin $2 \mathrm{~g}$ for 20 days, tetracycline $1 \mathrm{~g}$ for seven days, gentamycin $180 \mathrm{mg}$ for 36 days, and cephalexin $1 \mathrm{~g}$ for 14 days. The lumbar puncture revealed clear colourless spinal fluid under a pressure of $170 \mathrm{mmH}_{2} \mathrm{O}$ containing 190 erythrocytes, eight polymorphonuclear leucocytes, seven lymphocytes, protein $1.08 \mathrm{~g} / 1$, gamma globulin $6 \%$, and glucose $3.6 \mathrm{mmol} / 1(64 \mathrm{mg} / \mathrm{dl})$. The Indian ink preparations, cultures, and cytology of the spinal fluid were all negative for organisms. Repeated lumbar puncture one month later showed an opening pressure of $290 \mathrm{mmH}_{2} \mathrm{O}$, clear colourless spinal fluid containing no cells, protein $0.83 \mathrm{~g} / 1$, and glucose $2.8 \mathrm{mmol} / 1$ $(50 \mathrm{mg} / \mathrm{dl})$. The cultures and cytology were again negative. The patient showed fluctuations in his neurological status and was eventually discharged on anticonvulsants and dexamethasone $12 \mathrm{mg} /$ day.

In October 1973 he was readmitted to the Boston VA Hospital because of seizures, incontinence, and deterioration of gait. The general physical examination was unremarkable. His speech was paraphasic and meaningless. He did not seem to understand spoken or written language and did not follow commands. The optic discs were pale but the rest of the cranial nerves were normal. The motor power was good, the deep tendon reflexes symmetrical, and the plantar responses were tonic flexor. Pain was perceived throughout. An EEG showed diffuse theta and delta slow activity with occasional right midtemporal sharp activity. The lumbar puncture revealed clear colourless cerebrospinal fluid containing three erythrocytes, 12 polymorphonuclear leucocytes, and two lymphocytes $/ \mathrm{mm}^{3}$, protein $0.33 \mathrm{~g} / 1$, gamma globulin $13 \%$, and glucose $3.7 \mathrm{mmol} / 1(66 \mathrm{mg} / \mathrm{dl})$. Indian ink preparations, cultures, cytology, and VDRL were all negative. A three vessels arteriogram and pneumoencephalogram disclosed no abnormalities. He gradually became mute and less alert, but then improved again. Repeat lumbar puncture six weeks later showed clear colourless spinal fluid under a pressure of $220 \mathrm{mmH}_{2} \mathrm{O}$, containing 120 polymorphonuclear leucocytes $/ \mathrm{mm}^{3}$, protein $0.48 \mathrm{~g} / 1$, and glucose $3.6 \mathrm{mmol} / 1(65 \mathrm{mg} / \mathrm{dl})$. Indian ink preparations and cultures were again negative. $\mathrm{He}$ was ob- served to have a generalised seizure with turning of the head and eyes to the right. A repeated pneumoencephalogram showed slight enlargement of the ventricles. The patient developed nystagmus on gaze to the left and the plantar responses became extensor. Cisternal puncture revealed clear cerebrospinal fluid under a pressure of $275 \mathrm{mmH}_{2} \mathrm{O}$, containing one erythrocyte, two lymphocytes, protein $0.55 \mathrm{~g} / 1$, and glucose $2.8 \mathrm{mmol} / 1(50 \mathrm{mg} / \mathrm{dl})$. Cultures grew alpha Streptococcus in thioglycolate broth only. A ventriculo-atrial shunt was inserted. He gradually became less responsive and lapsed into coma. The pupils were $6 \mathrm{~mm}$, equal and reactive to light. There were no decerebration signs on painful stimulation. He died on 22 March 1974.

\section{PATHOLOGICAL FINDINGS}

At necropsy no abnormalities were seen with the naked eye in any viscera except for petechial haemorrhages in the stomach. The microscopic study of the organs was also entirely negative except for superficial erosions of the stomach mucosa and mild terminal bronchopneumonia. Careful attention to the intestines, peripheral and mesenteric lymph nodes, heart, pericardium, liver, and spleen with the use of special stains including PAS and methenamine silver failed to demonstrate any lesions.

The brain weighed $1750 \mathrm{~g}$. A patent ventriculoatrial shunt was in place. The amputation of the tip of the left temporal lobe was evident. The brain was diffusely swollen with flattening of the gyri and mild moulding against the tentorial edge but no other abnormalities were visible on its surface. When the sectioning was carried out after fixation in formalin, a most unusual picture became evident. The entire cerebral cortical ribbon was studded with an extraordinary number of minute lesions (Fig. 1). These were roughly circular or oval, measuring on the average $2 \mathrm{~mm}$ in diameter. In places the lesions were confluent. They were recognisable by a chalky yellowishwhite colour which was most intense at the periphery of each lesion, outlining it like a ring. Less numerous lesions of this type were present in the caudate nucleus and putamen, and a few could be seen in the thalamus and in the cerebellar cortex. The white matter was entirely free of lesions. None were visible in the brain stem or the spinal cord. Granular ependymitis was present throughout the ventricular system.

Many blocks of tissue were processed in paraffin and the sections stained with haematoxylin and eosin (H and $\mathrm{E}$ ), luxol fast blue, cresyl violet, phosphotungstic acid haematoxylin (PTAH), 


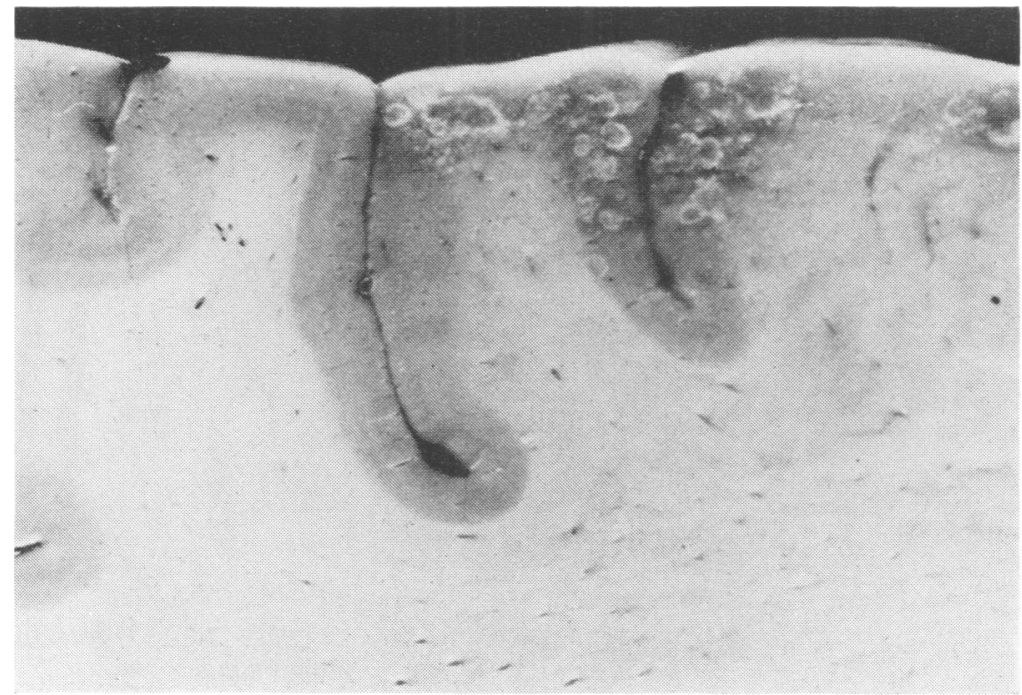

Fig. 1 Lesions in the parietal cortex. $\times 2$.

Masson trichrome, periodic acid Schiff (PAS), methenamine silver, and Gram stain.

Some sections of the cerebral cortex showed a multitude of lesions many of which were confluent (Fig. 2). Three types of lesions could be distinguished. The first, which was most frequent, consisted of a massive aggregate of macrophages containing material which stained faintly blue with $\mathrm{H}$ and $\mathrm{E}$ but was brilliantly red with PAS (Fig. 3) and intensely black with methenamine silver (Fig. 2). In most lesions two zones of macrophages could be distinguished from the standpoint of the tinctorial properties of their content. In the macrophages located at the periphery of the lesions Gram positive organisms could be seen and the staining with PAS was finely stippled and only moderate in intensity (Fig. 3). In the centrally located macrophages no organisms were visible on Gram stain and the staining with PAS was in coarser clumps and very intense. Some lesions contained bundles of collagen inside them and the brain tissue immediately around the lesions had reactive and hypertrophic astrocytes. An occasional lesion had a larger blood vessel in its

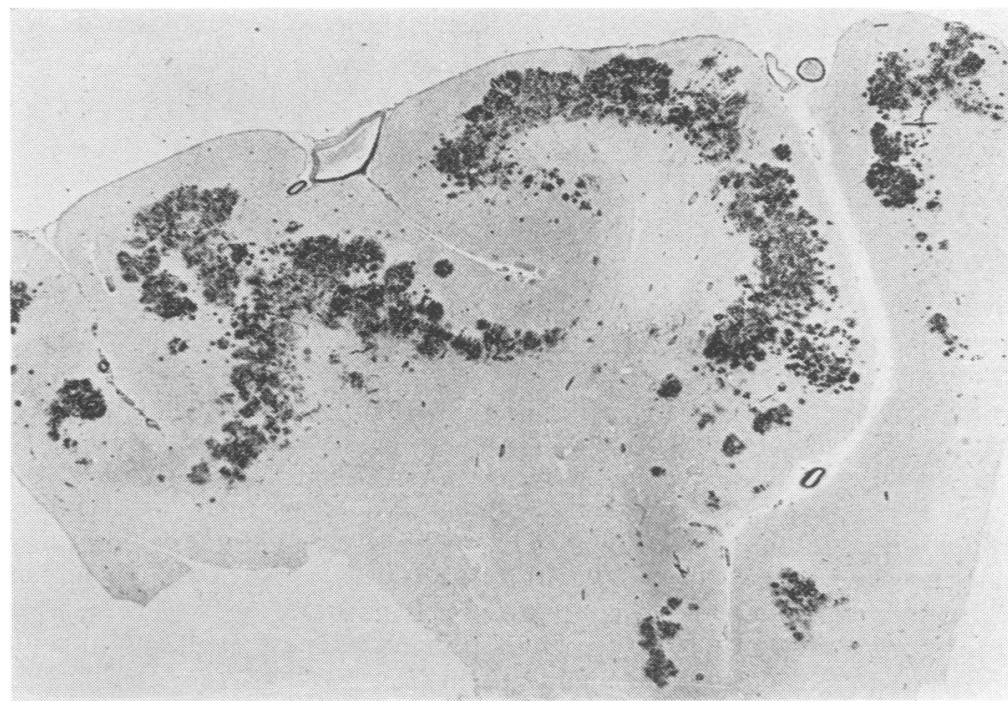

Fig. 2 Lesions in the frontal cortex. Methenamine silver stain. $\times 4$. 


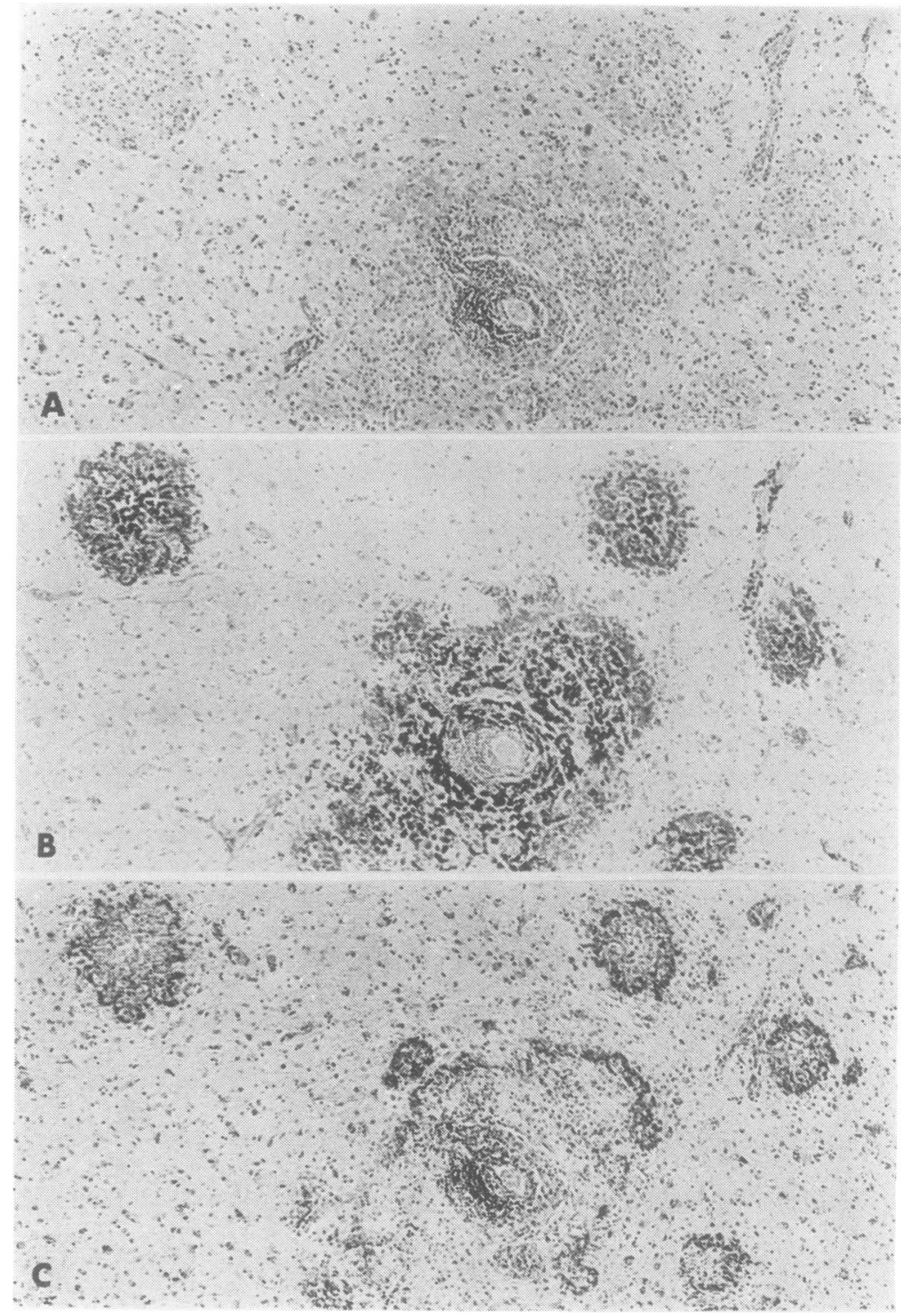

Fig. 3 Older lesions consisting of a mass of macrophages staining faintly with $H$ and $E$ $(A)$ and strongly with $P A S(B)$. The macrophages located at the periphery stain less intensely with $P A S(B)$ and contain Gram positive organisms $(C) . \times 65$.

centre (Fig. 3). Perivascular lymphocytes were seen in a few lesions and occasionally in an apparently unaffected area of the brain.

A second type of lesion was much smaller and was not visible grossly. Microscopically, it was found in the thalamus and throughout the tegmentum of the brain stem. With $\mathrm{H}$ and $\mathrm{E}$ it appeared simply as a pleomorphic microglial nodule but with PAS it had the staining characteristics of the peripheral macrophages of the large lesions (Fig. 4). With bacterial stains it contained Gram positive organisms.
A third type of lesion was seen very rarely in the cerebral cortex and in the basal ganglia. It consisted of an area of shrinkage and astrocytic scarring of the tissue comparable in size to that of a medium size or large lesion of the first type.

The leptomeninges showed a light infiltration with lymphocytes and occasional macrophages filled with PAS positive material. There was striking granular ependymitis. Most of the ependymal cells contained PAS positive material which was also present in macrophages shedding into the ventricular system (Fig. 5). 


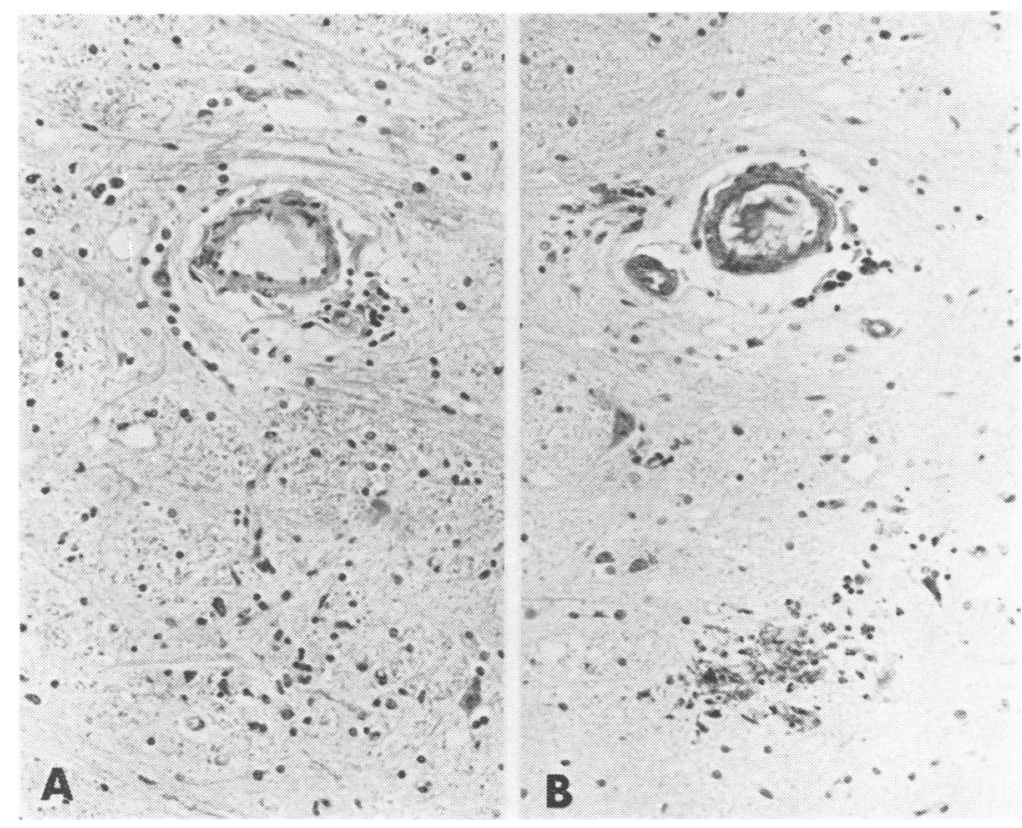

Fig. 4 Recent lesions appearing only as pleomorphic microglial nodule with $H$ and $E(A)$ but staining with $P A S(B) . \times 200$.

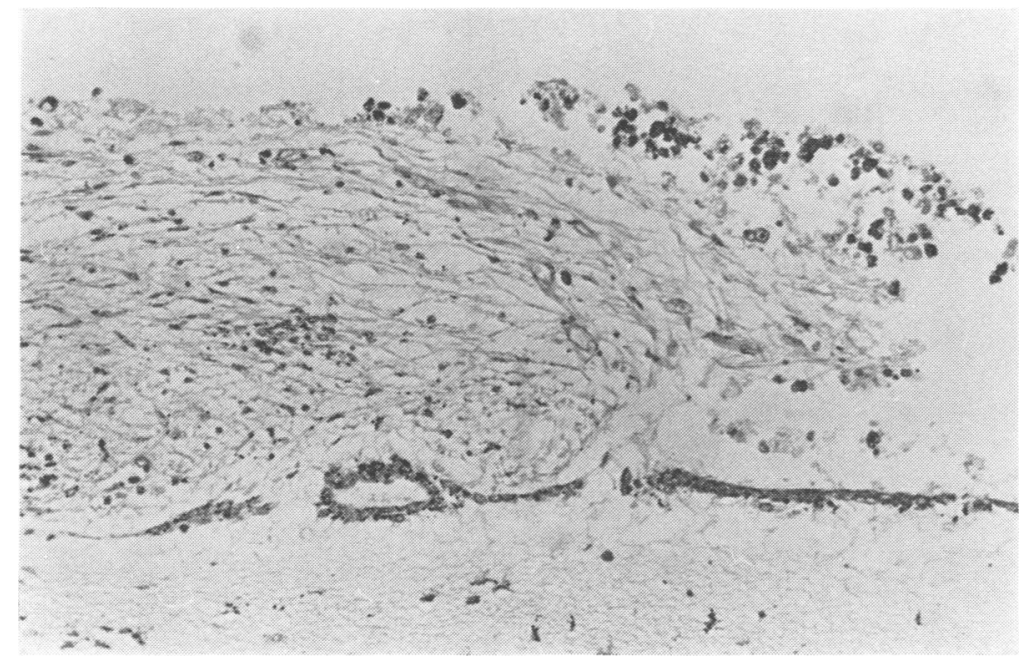

Fig. 5 Granular ependymitis and macrophages containing $P A S$ positive material shedding into the ventricle. PAS stain. $\times 180$.

Some blocks of tissue from the peripheral and central portions of the grossly visible lesions of the first type were processed for electron microscopy. The peripheral portions of the lesions revealed the macrophages to contain many relatively well-preserved bacilli (Fig. 6). By contrast in the central portions of the lesions the macrophages were filled with membrane bounded structures of dimensions similar to those of bacilli as well as thinner tubular and serpiginous forms (Fig. 7).

\section{Discussion}

Whipple (1907) characterised the disease pathologically to consist of accumulations of macrophages filled with lipidin the mucosa of the small intestine and in the mesenteric lymph nodes. Subsequently the disease was shown to affect many other tissues and organs (Sieracki, 1958; Sieracki and Fine, 1959). The content of the macrophages was found to stain with a unique brilliance with PAS (Black-Schaffer, 1949), to be finely granular 

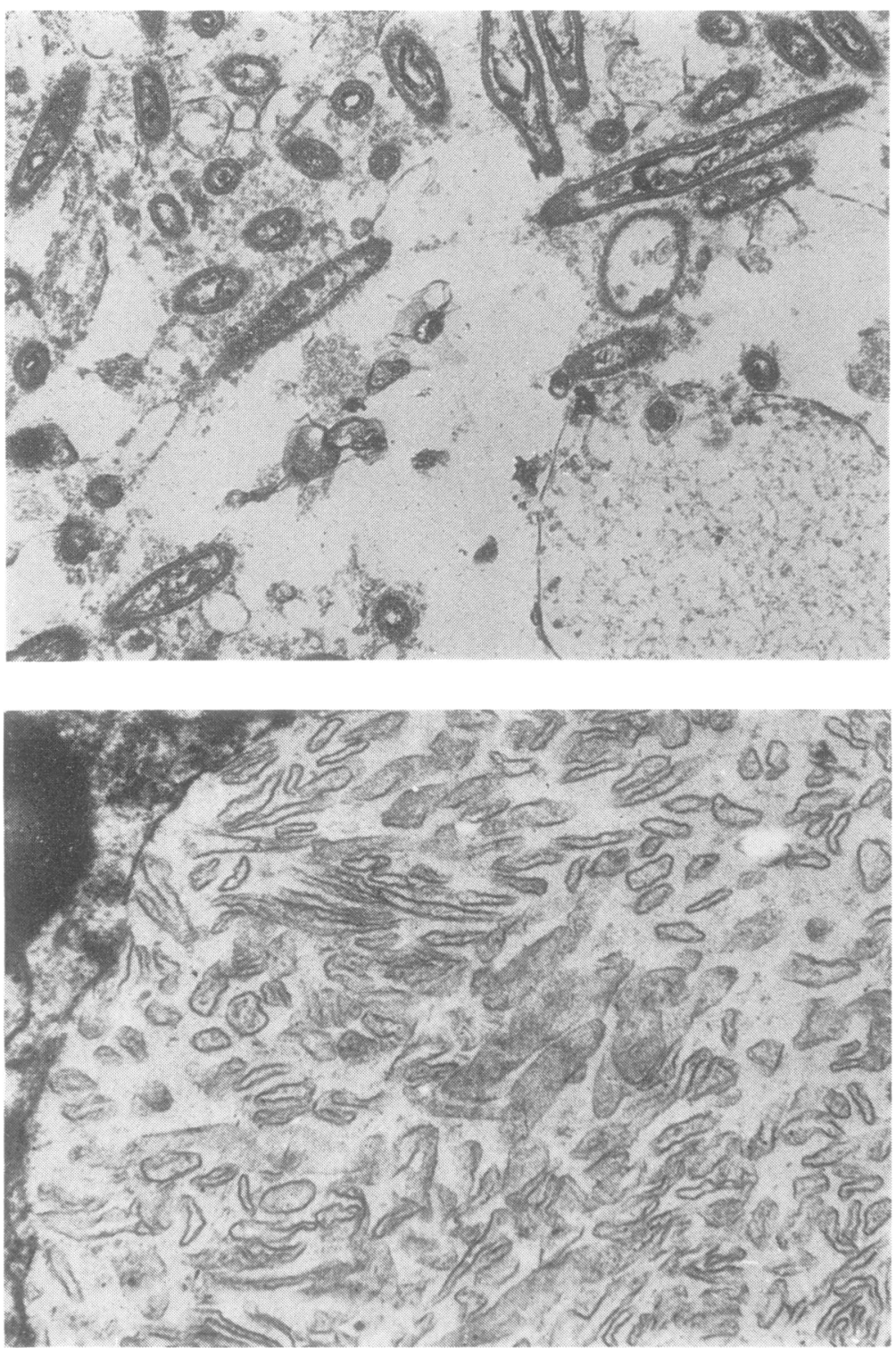

Fig. 6 Bacilli in macrophages located at the periphery of the older lesions. $\times 20000$.

Fig. 7 Membranous structures in macrophages located in the centre of the older lesions. $\times 30000$.
(Sieracki, 1958; Sieracki and Fine, 1959), and to stain also very intensely with methenamine silver (Chears and Ashworth, 1961; Yardley and Hendrix, 1961). Using the Levaditi method, Whipple (1907) demonstrated rod bodies in the intestinal lesions and thought that these might be microorganisms which could conceivably cause the disease. Recently by electron microscopy the macrophages were shown to contain bacilli in intact form as well as in various stages of degradation into membrane-like structures derived from bacterial walls and responsible for the strong PAS staining (Chears and Ashworth, 1961; Yardley and Hendrix, 1961; Kurtz et al., 1962; Kent et al., 1963; Trier et al., 1965). Antibiotic therapy resulted in improvement of the gastrointestinal symptoms (Paulley, 1952; England et al., 1960; Kent et al., 1963; Ashworth et al., 1964; Trier et $a l ., 1965)$ and of the pathological changes in the small intestine (Kent et al., 1963; Ashworth et al., 1964; Trier et al., 1965). A number of bacteria were cultured from the lesions or from the blood, 
including atypical alpha streptococci (Charache et al., 1966; Knox et al., 1968; Clany et al., 1975), brucella (Kok et al., 1964), aerobic (Kent et al., 1963; Dybkaer and Kok, 1965) and anaerobic (Caravati et al., 1963; Prevot and Morel, 1964; Greenberger et al., 1971) corynebacteriae and haemophilus (Kok et al., 1964; Kjaerheim et al., 1966). The aetiological role of any of these organisms remains to be proven, although a bacterial participation in the disease is firmly established both by the electron microscope findings and by the response of the disease to antibiotic therapy. It has been suggested that the action of the microorganisms in this condition may occur on a background of defective immunological mechanisms (Maxwell et al., 1968; Groll et al., 1972; Martin et al., 1972; Cochran et al., 1973).

The brain can be affected occasionally by the disease. The lesions in the central nervous system are identical to those in the small intestine both with the light (Sieracki et al., 1960) and the electron microscope (Groodt-Lassell and Martin, 1969; Schochet and Lampert, 1969). There are 21 cases in the literature in which the brain was found to contain the lesions at necropsy (Rutishauser and Borer, 1960; Sieracki et al., 1960; Krücke and Stochdorph, 1962; Lampert et al., 1962; Badenoch et al., 1963; Smith et al., 1965; Schwartzová et al., 1967; Groodt-Lassell and Martin, 1969; Minauf and Stochdorph, 1969; Schochet and Lampert, 1969; Stoupel et al., 1969; Switz et al., 1969; Kodousek and Kojecki, 1971; Janota, 1974; Kitamura, 1975; Silbert et al., 1976). In two of these (Rutishauser and Borer, 1960; Janota, 1974) the examination of the important organs was not available but the patients had clinical evidence of systemic involvement. All the other patients had systemic symptoms and pathological changes in many organs and tissues. The present case is unique in that both the symptoms and the pathological changes were confined to the brain.

The neuropathological findings in our case are remarkable from several points of view. In the typical lesion of the first type (Fig. 3) the peripheral rim of macrophages contained Gram positive organisms, moderately intense PAS staining material, and many bacilli demonstrable by electron microscopy. By contrast, the more centrally located macrophages had no organisms on Gram stain, their content stained intensely with PAS and ultrastructurally had no demonstrable bacteria, being filled only with empty bacterial 'ghost' and membranous structure. These differences lead us to conclude that the peripheral portion of the lesion is more recent while the central part is old. It is in this older part which contains only degraded bacteria that the staining with PAS is most intense. This finding supports the view that the brilliant staining of the macrophages with PAS is due to the degraded packed bacterial membrane remnants. Correlating the gross and the microscopic findings in the lesions of the first type, we conclude that the yellowishwhite ring outlining the lesion on naked eye inspection of the brain (Fig. 1) is due to the different content of the peripherally located macrophages.

The second type of lesion (Fig. 4) is also of considerable interest since with $\mathrm{H}$ and $\mathrm{E}$ it appeared only as a pleomorphic microglial nodule while with PAS it showed the typical staining and with the Gram method had demonstrable organisms. We interpret these to be early small lesions which do not yet contain macrophages in the form of compound granular cells. It is important to know that such lesions exist since if they are the only ones present in a biopsy or a section of brain, the nature of the process will not be recognised unless the PAS stain is used.

The third type of lesion, which was rare, consisted of minute scars which must represent lesions which have healed either spontaneously or as a result of antibiotic therapy.

Reviewing the clinical manifestations of the reported cases of Whipple's disease with verified cerebral pathology, the patients first developed systemic symptoms such as diarrhoea, arthritis, fever, malaise, and lymphadenopathy. In some cases the presence of a systemic disease was readily apparent, while in others there were only mild symptoms such as arthralgia which seemed nonspecific. The neurological manifestations followed the systemic ones by months or years. The picture was that of progressive dementia with rather inconspicuous pyramidal or extrapyramidal signs, ending in an akinetic mute state and eventual coma over a period of a few months to seven years (Krücke and Stochdorph, 1962: Lampert et al., 1962; Badenoch et al., 1963; Smith et al., 1965; Schwartzová et al., 1967; Minauf and Stochdorph, 1969; Silbert et al., 1976). Several patients had disorders of eye movements (Lampert et al., 1962; Badenoch et al., 1963; Smith et al., 1965; Minauf and Stochdorph 1969; Stoupel et al., 1969) and seizures or myoclonus (Lampert et al., 1962; Smith et al., 1965; Minauf and Stochdorph, 1969; Stoupel et al., 1969). One patien had papilloedema (Lampert et al., 1962). Two cases were not noted to have neurological symptoms or signs in spite of the presence of 
lesions in the brain (Sieracki et al., 1960). Our patient was unique in several respects. He did not have preceding systemic symptoms. He began having seizures, underwent mental changes, and developed evidence of a space-occupying lesion. Subsequently, he continued to deteriorate mentally over a period of four years ending in coma. Fever was present intermittently throughout his illness.

The cerebrospinal fluid findings in the cases reported in the literature were given in six instances (Lampert et al., 1962; Badenoch et al., 1963; Minauf and Stochdorph, 1969; Stoupel et al., 1969; Switz et al., 1969; Silbert et al., 1976). They ranged from normal to elevated pressure, no erythrocytes, 0-3 polymorphonuclear leucocytes, and $0-420$ lymphocytes $/ \mathrm{mm}^{3}$. The protein ranged from $0.21-0.85 \mathrm{~g} / 1$ being elevated in only two cases (Switz et al., 1969; Silbert et al., 1976), in spite of the pleocytosis present in the other cases. The sugar content was always normal. In our patient the cerebrospinal fluid pressure was usually normal but on a few occasions was elevated. It contained 0-950 erythrocytes, 0-120 polymorphonuclear leucocytes, and 0-45 lymphocytes $/ \mathrm{mm}^{3}$. The protein ranged from $0.23-1.08 \mathrm{~g} / 1$ and the sugar content was never decreased.

From the above considerations it is apparent that the diagnosis of Whipple's disease of the brain may be extremely difficult when the symptoms occur without the systemic manifestations of the disorder. The clinical picture of the cerebral involvement is rather non-specific and similar to that of vasculitis and other subacute or chronic encephalopathies. When the systemic manifestations are lacking, a brain biopsy may be diagnostic if the PAS stain is used. The examination of a spinal fluid cell block with the electron microscope may be of some help.

The authors wish to thank Dr Lysia S. Forno from the Neuropathology Laboratory, Veterans Administration Hospital, Palo Alto, California and Dr Joseph Incze, Department of Pathology, Boston Veterans Administration Hospital for their help with the electron microscope studies and electron micrographs. The technical and secretarial assistance of Ms Rita Chumbanis and Ms Linda Frome are greatly appreciated.

\section{References}

Ashworth, C. T., Douglas, F. C., Reynolds, R. C., and Thomas, P. J. (1964). Bacillus like bodies in Whipple's disease; disappearance with clinical remission after antibiotic therapy. American Journal of Medicine, 37, 481-490.

Badenoch, J., Richards, W. C. D., and Oppenheimer,
D. R. (1963). Encephalopathy in a case of Whipple's disease. Journal of Neurology, Neurosurgery, and Psychiatry, 26, 203-210.

Black-Schaffer, B. (1949). Tinctoral demonstration of glycoprotein in Whipple's disease. Proceedings of the Society of Experimental Biology and Medicine, 72, 225-227.

Caravati, C. M., Litch, M., Weisiger, B. B., Ragland, S., and Berliner, H. (1963). Diagnosis of Whipple's disease by rectal biopsy with a report of three additional cases. Annals of Internal Medicine, 58, 166170.

Charache, P., Bayless, T. M., Shelly, W. M., and Hendrix, T. R. (1966). Atypical bacteria in Whipple's disease. Transactions of the Association of American Physicians, 79, 399-408.

Chears, W. C., Jr., and Ashworth, C. T. (1961). Electron microscopic study of the intestinal mucosa in Whipple's disease-demonstration of encapsulated bacilliform bodies in the lesion. Gastroenterology, 41, 129-138.

Clany, R. L., Tomkins, W. A. F., Muckle, T. J., Richardson, H., and Rawls, W. E. (1975). Isolation and characterization of an aetiological agent in Whipple's disease. British Medical Journal, 3, 568570.

Cochran, M., Gallagher, J. C., Cook, M. G., and Peacock, M. (1973). Hypogamma-globulin in Whipple's disease. Postgraduate Medical Journal, 49, 355-358.

Dybkaer, R., and Kok, N. (1965). Bacteria in Whipple's disease. 3. Studies in two patients of antibodies in serum and cutaneous hypersensitivity against some bacterial antigens. Acta Pathologica et Microbiologica Scandinavica, 64, 373-380.

England, M. T., French, J. M., and Ranson (1960). Antibiotic control of diarrhea in Whipple's disease. Gastroenterology, 39, 219-231.

Greenberger, N. J., Delor, C. J., Fisher, J., Perkins, R. L., Murad, T., and Kapral, F. (1971). Whipple's disease. Characterization of anaerobic corynebacteria and demonstration of bacilli in vascular endothelium. Digestive Diseases, 16, 1127-1136.

Groll, A., Valberg, L. S., Simon, J. B., Eidinger, D., Wilson, B. and Forsdyke D. R. (1972). Immunological defect in Whipple's disease. Gastroenterology, 63, 943-950.

Groodt-Lassell, M. de, and Martin, J. J. (1969). Etude ultrastructurale des lésions du système nerveux central dans la maladie de Whipple. Pathologie-Biologie, 17, 121-131.

Hendrix, J. P., Black-Schaffer, B., Withers, R. W., and Handler, P. (1950). Whipple's intestinal lipodystrophy: Report of 4 cases. Archives of Internal Medicine, 85, 91-131.

Janota, I. (1974). Whipple's disease with neurological presentation. Presented at the British Neuropathological Society, 24 July 1971, quoted by Pallis, C. A. and Lewis, P. D.: Whipple's disease and the nervous system. In Neurology of the Gastrointestinal Diseases, pp. 207-214. W. B. Saunders Co: Philadelphia. 
Kent, T. H., Layton, J. M., Clifton, J. A., and Schedl, M. P. (1963). Whipple's disease; Light and electron microscopic studies combined with clinical studies suggesting an infective nature. Laboratory Investigation, 12, 1163-1178.

Kitamura, T. (1975). Brain involvement in Whipple's disease. A case report. Acta Neuropathologica (Berlin), 33, 275-278.

Kjaerheim, A., Midwedt, T., Skrede, S., and Gjone, E. (1966). Bacteria in Whipple's disease-isolation of a haemophilus strain from the jejunal propria. Acta Pathologica et Microbiologica Scandinavica, 66, 135-143.

Knox, D. L., Bayless, T. M., Yardley, J. M., and Charache, P. (1968). Whipple's disease presenting with ocular inflammation and minimal intestinal symptoms. Johns Hopkins Medical Journal, 123, 175-182.

Kodousek, R., and Kojecki, Z. (1971). On the basis of cerebral lesions in Whipple's disease. Review of Czechoslovak Medicine, 17, 137-142.

Kok, N., Dybkaer, R., and Rostgaard, J. (1964). Bacteria in Whipple's disease. Results of cultivation from repeated jejunal biopsies prior to, during and after effective antibiotic treatment. Acta Pathologica et Microbiologica Scandinavica, 60, 431-449.

Krücke, W., and Stochdorph, O. (1962). Über Veränderungen im Zentralnervensystem bei Whipple's cher Krankheit. Verhandlungen der Deutschen Gesellschaft fur Pathologie, 46, 198-202.

Kurtz, S. M., Davis, T. D., Jr., and Ruffin, J. M. (1962). Light and electron microscopic studies of Whipple's disease. Laboratory Investigation, 11, 653665.

Lampert, P., Tom, M. I., and Cummings, J. N. (1962). Encephalopathy in Whipple's disease. A histochemical study. Neurology (Minneapolis), 12, 65-71.

Maizel, H., Ruffin, J. M., and Dobbins, W. O., (1970). Whipple's disease: A review of the literature since 1950. Medicine (Baltimore), 49, 175-205.

Martin, F. F., Vilseck, J., Dobbins, W. O., III, Buckley, C. E., and Tyor, M. P. (1972). Immunological alterations of patients with treated Whipple's disease. Gastroenterology, 63, 6-18.

Maxwell, J. D., Ferguson, A., McKay, A. M., Murie, R. C., and Watson, W. C. (1968). Lymphocytes in Whipple's disease. Lancet, 1, 887-889.

Minauf, M., and Stochdorph, O. (1969). Das ZNS bei morbus Whipple. Archiv für Psychiatrie und Nervenkrankheiten, 212, 180-199.

Paulley, J. W. (1952). A case of Whipple's disease (intestinal lipodystrophy). Gastroenterology, 22, 128-133.

Prevot, A. R.. and Morel, C. (1964). Nouveau cas de maladie de Whipple a corynebacterium anaerobium guérie par antibiothérapie. Bulletin de l'Académie Nationale de Médecine (Paris), 148, 540-544.

Rutishauser, E., and Borer, F. (1960). Aspects morphologigues dans la pathology de l'intestin grêle. II La maladie de Whipple. Dündarmpathologia. Bibliotheca Gastroentologica, pp. 80-109. (Cited by Minauf and Stochdorph). S. Karger: Basel, New York.

Schochet, S. S., and Lampert, P. W. (1969). Granulomatous encephalitis in Whipple's disease. Acta Neuropathologica (Berlin), 13, 1-11.

Schwartzová, K., Schwárz, A., and Marck, J. (1967). Whipplova choroba S. neurologickou symptomatologii. Plženský Lékarsky Sbornik, 28, 99-108.

Sieracki, J. C. (1958). Whipple's disease; observations on systemic involvement. I. Cytologic observations. Archives of Pathology, 66, 464-467.

Sieracki, J. C., and Fine, G. (1959). Whipple's disease; observations on systemic involvement. II. Gross and histologic observations. Archives of Pathology, 67, 85-94.

Sieracki, J. C., Fine, G., Horn, R. C., and Bebin, J. (1960). Central nervous system involvement in Whipple's disease. Journal of Neuropathology and Experimental Neurology, 19, 70-75.

Silbert, S., Parker, E., and Horenstein, S. (1976). Whipple's disease of the central nervous system. Acta Neuropathologica (Berlin), 36, 31-38.

Smith, W. T., French, J. M., Gottsman, M., Smith, A. J., and Wakes-Miller, J. A. (1965). Cerebral complications of Whipple's disease. Brain, 88, 137149.

Stoupel, N., Monseu, G., Pardoe, A., Heimann, R., and Martin, J. J. (1969). Encephalitis with myoclonus in Whipple's disease. Journal of Neurology, Neurosurgery, and Psychiatry, 32, 338-343.

Switz, D. M., Casey, T. R., and Bogaty, G. V. (1969). Whipple's disease and papilledema. Archives of Internal Medicine, 123, 74-77.

Trier, J. S., Phelps, P. C., Eidelman, S., and Rubin, C. E. (1965). Whipple's disease: Light and electron microscope correlation of jejunal mucosal histology with antibiotic treatment and clinical status. Gastroenterology, 48, 684-707.

Whipple, G. H. (1907). A hitherto undescribed disease characterized anatomically by deposits of fat and fatty acids in the intestinal mesenteric lymphatic tissues. Bulletin of the Johns Hopkins Hospital, 18, 382-391.

Yardley. J. H., and Hendrix, T. R. (1961). Combined electron and light microscopy in Whipple's diseasedemonstration of "bacillary bodies" in the intestine. Bulletin of the Johns Hopkins Hospital, 109, 80-98. 